\title{
Experience report and data visualization to evaluate a game programming project aimed for girls using Scratch tool
}

\author{
Ana Laura Soares ${ }^{1}$, Maria Eugênia A. Ferreira ${ }^{1}$, Danielli A. Lima ${ }^{1}$ \\ ${ }^{1}$ Laboratório de Inteligência Computacional e Robótica (LICRo) \\ Instituto Federal do Triângulo Mineiro (IFTM) - Campus Patrocínio \\ Av. Líria Terezinha Lassi Capuano, 255 - 38.740-000 - Patrocínio - MG - Brasil \\ analawra@outlook.com, meugeniadeavila@gmail.com, danielli@iftm.edu.br
}

\begin{abstract}
The inclusion of women in technology has increased in recent years, but the number of women in technology is still much smaller compared to male involvement. Many factors make women not part of the information technology field. These factors include cultural, social factors of lack of information about the area. Thus, this paper aims to understand some of the factors that lead women to look less for professional areas involving science and technology. This article presents the state of the art of science and technology projects that have been aimed at women around the world. In addition, a questionnaire was applied in order to present some of the factors that can affect the performance of girls in projects in the field of Exact Sciences. Among the variables studied, the one that had the greatest correlation with the worst performances achieved by the girls was the absence of technology and internet at home. Furthermore, a quali-quantitative analysis shows the importance of carrying out projects that involve women in science and technology.
\end{abstract}

\section{Introduction}

The world of science, technology, engineering and mathematics (STEM) areas was known to be a "bubble club", and this expression comes because male scholars and practitioners historically dominate these areas. Even with the achievements made by women to get their places in universities, the number of men remained the vast majority in STEM studies [Zeldin et al. 2008]. There is a constant struggle of women linked to the demand for basic rights, such as education, voting and work. Demands for women's rights began in the 18th century [Kimmel et al. 2005]. From this moment on, women have gained several rights that were previously given only to men. However, in many countries it was not possible to achieve these rights due to cultural issues [Guiso et al. 2008]. In countries where the cultural situation are strongest, girls remain the smallest in STEM areas, and in some countries, women are prohibit from studying.

This factor itself can be a deterrent to female participation in schooling [Valentine and Darkenwald 1990]. Difficulties of accessibility, lack of resources and low teacher quality and morale are widespread. In particular, the lack of female primary teachers in rural areas is a real problem. Parents are, in some countries, very reluctant indeed to send daughters to school if there is no female teacher, and the facilities for the accommodation and security of such teachers are usually absent or inadequate [Hill et al. 2010]. The organization of schooling in terms of the daily and seasonal imperatives of local economies usually renders it dysfunctional, and the curriculum is often unattractive in instrumental terms. At secondary level, in addition to the lack of (accessible) places, 
problems of cost, direct and hidden are acute, and there is a considerable need for more single-sex (girls) schools, some with secure boarding facilities and scholarship schemes to enable participation. Vocational education is weak and schemes open to girls in STEM are particularly useful. There is still a widespread problem of gender bias in books and materials [Valentine and Darkenwald 1990].

The number of women in science and engineering is growing, yet men continue to outnumber women, especially at the upper levels of these professions. In elementary, middle, and high school, girls and boys take STEM courses in roughly equal numbers, and about as many girls as boys leave high school prepared to pursue science and engineering majors in college [Hill and King 1995]. Often technology could reduce the teacher-student transnational gap, increasing the success rates of both girls and boys [Eccles et al. 1990], but especially by girls in schools [Lima et al. 2017, Alves and Lima 2018]. An important factor in the growth of women in schools and universities was their support from organizations [Eccles et al. 1990].

Thus, an important tool to foster the growth of girls in STEM is to create projects for these girls to realize the importance of this area within the economic and social context. Especially for the Information Technology (IT) area, which has a high demand for professionals. Thus, the IT for Girls is a project created in 2019 and aimed to contribute to the growth of the number of women in Information Technology courses, as well as in the labor market of this study area. The project allows high school students to have initial contact with topics related to programming logic for many purposes, such as game development or robotics, for example. The project was developed to deepen the concepts related to the development of games for high school students.

Thus, this paper aims to report the experience of an extension project for teenagers girls in the area of STEM education, more specifically in the area of game creation using the Scratch tool. A systematic review is presented here for show the state of art of girls in STEM area. Subsequently, a data analysis will be performed in order to present the factors that affect girls choosing "IT for girls" project in STEM area. This report also shows, which factors could help girls learn game programming, such as internet and computer at home. Each of these analyzes will be evaluated later in this report, and the results will be discussed and detailed.

\section{Related Works}

Through educational programming games or robots, students will be able to explore ideas and discover new ways in the application of acquired concepts. However, women are not interested in STEM areas. There is a record of a wide gender inequality in STEM areas either as students or teachers. In this section we present STEM projects targeted for women during the last four years by Google Scholar search based on the research of [Lima et al. 2021]. The research returned 15 results (papers) from different countries as is possible to see in Figure 1. The search string was: "project AND (STEM OR robotics OR 'programming games') AND (girls OR girl OR women OR woman OR female)". We applied filters using the StArt Tool, in which duplicate articles were unconsidered, leaving 14 articles for the last 2 stages. Papers that were not in English or less than 3 pages were also excluded. Finally, 8 papers were remained and discussed herein. Figure 2(a) shows the relation of number of authors involved in STEM projects for girls and nationality of first author. Figure 2(b) shows the percentage that the each country contributed in amount of accepted paper of our systematic review of literature (SRL) presented herein. 


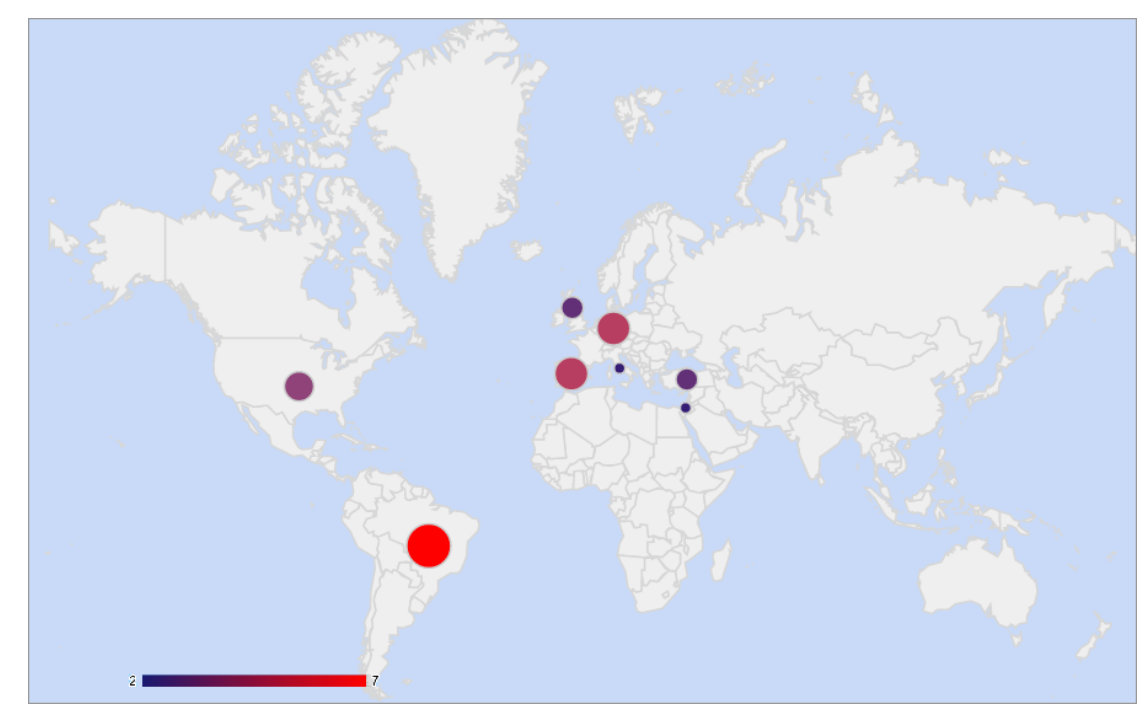

Figure 1. World map created from the results of the first phase of the systematic review search, only eight countries appeared.

In paper [Schnittker et al. 2018] authors explored professionals' perceptions influence of young women in STEM, considering the period they start working and their career progression in Germany. This study improved women career progression in STEM areas and their advancement in comparison to men's career. In [Mich and Ghislandi 2019] paper the authors present a study intended to investigate the effects on children's career choices of the Roboestate project from Italy, a summer camp aimed at introducing boys, but especially girls, to STEMs through educational robotics activities. The authors conducted a quali-quantitative analysis. They affirmed that project-like courses increase boys', and especially girls', interest in STEM careers.

In [García-Holgado et al. 2019] authors reported that are significant progress in gender equality in the last decades. The W-STEM project aims to attract more girls for STEM area in Latin America, including, Chile, Colombia, Costa Rica, Ecuador and Mexico. Authors in [Mirici et al. 2019] investigated the women in STEM Science Teachers careers in Turkey, considering their perceptions for writing projects and (dis)assimilation in the education process, taking account Biology, Science, Maths in Primary Education candidate teachers.

In paper [Ferreira et al. 2019] the authors discussed a project called "Elas na Robótica" that discussed an awarded project in the interior of Brazil, they showed the sentiment analysis from many female students and teachers that worked in a robotics and programming project. The authors showed that is important for those girls to participate in STEM' projects only for girls, because it encourages them to learn programming and robotics in practice. Also in the other paper they published in 2021 [Lima et al. 2021], that takes into consideration the final girls and teachers project evaluation in programming and robotics area.

In paper [Glover et al. 2018] the author discussed YPAR project for engage black girls from a low-income urban high school. Authors discovered after their research that ethnic factors could affect girls educational experience. Finally, in the paper [Davis 2020] the authors report on the delivery and impact of STEM Cymru 2 - an European Union funded project in Wales, United Kingdom. The project STEM Cymru 2 encouraged girls 
in STEM activities participation. These girls reported improvement in transferable skills, such as communication, problem-solving and also teamwork.

After analyzing the results from the SRL, it was possible to see that several countries take into account the greater engagement of women in STEM projects. Herein the

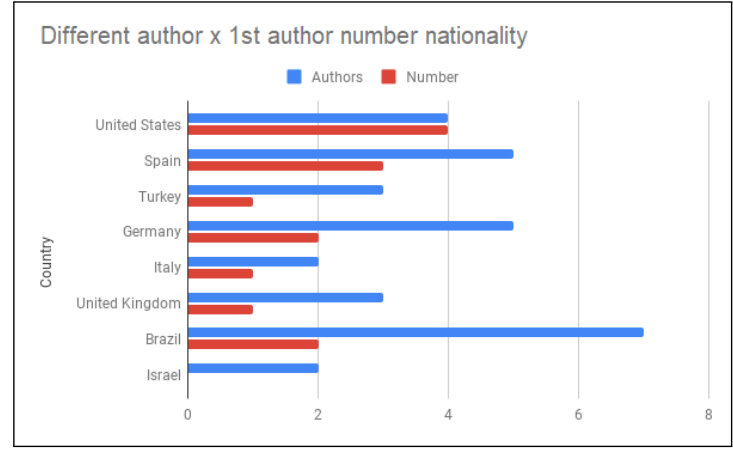

(a) Relation of number of authors and first author (b) nationality.

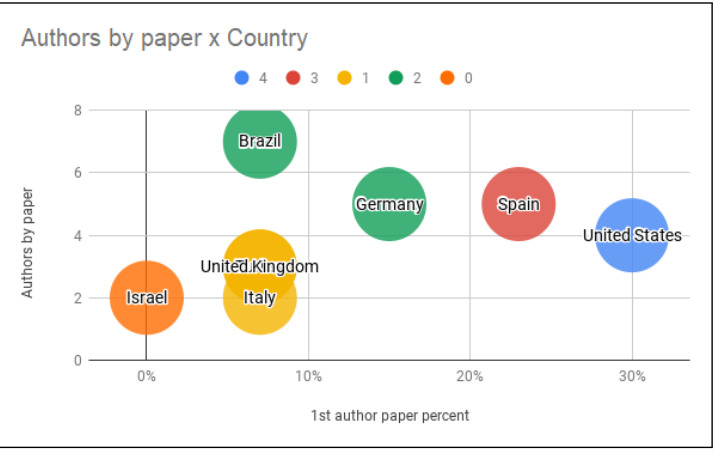

(b) Percentage by country publications considering 1 st author nationality.

\section{Figure 2. Relations between first author, country and number of authors involved in STEM projects targeted for girls.}

focus is show the female participation in a Game Programming Course called "IT for Girls" for preparing them for using Scratch Tool.

\section{Methodology}

In this experience report we seek to understand how our students enrolled in our extension project on games and computers related to concepts never before seen or weakly seen on questions of logic. For evaluate them, we used a questionnaire, which were extracted from OBI (Olimpiada Brasileira de Informática). It was possible to observe that some factors, such as having internet, cell phones or other electronic devices at home, could affect the development of our course, or even sought to be related to performance in this first test that was applied. We seek to make this analysis to improve the methodology of how our course should be taught. For example, not all students had computers or internet at home, therefore, no assignment could be asked for outside class. We also took into account whether the students live to set up our course plan.

The classes mostly were given to young girls who like to learn about game programming. Classes took place in the afternoons in laboratories with 30 machines. Initially, only young girls could apply in the course. However, later, we opened vacancies for boys who were interested in the theme. The course was taught involving basic and intermediate concepts about programming, animation and creating game scripts. The course was planned and built with the Scratch Platform. Scratch ${ }^{1}$ is a free, online community programming language, where students could create their own interactive stories, games, and animations.

Initially, as it will be possible to see in the results, the class contained students of different ages, students who were in elementary school aged 13 to students over the

\footnotetext{
${ }^{1}$ Since 2013 Scratch 2 has been available https: / / scratch. mit. edu / and as an application for Windows, OS X, and Linux. The source code for version 1.x is under the GPLv2 license. The 1st version was created in 2007 by the Massachusetts Institute of Technology (MIT) Media Lab.
} 
age of 18 , who had already completed high school. It was very interesting to be able to see the development of these students throughout the semester. Some students dropped out of classes, initially 25 students were enrolled in the course. Gradually, as the classes were being taught, some students ended up dropping out of the course. The space of the laboratories was large, and the students had a good interaction with the tutor. The students were building their knowledge and improving their learning.

All this construction was only possible because an initial profile of the students class was drawn. Firstly, evaluating their basic knowledge in logic, and later, evolving so that everyone reached a minimum knowledge so that classes could be taught in a more productive way. Thus, if everyone has a homogeneous logical reasoning for the execution of classes, the production would be more profitable. Thus, we observed the development of each of these students, which over time have evolved significantly. At the end of the course, to receive the certificate, students should present a game developed in Scratch for a tutor. At the end, only 11 students completed the course, only $44 \%$ of those enrolled. We know that there are still major dropouts in extension courses at the proposing institution, considering that it is a STEM project, we are pleased with the rate of students who have completed the IT for Girls course.

\section{Results}

As presented in the previous section, some variables before starting the course were evaluated to improve the paths to be taken. A new work plan was drawn up based on the knowledge of these variables. First, we carried out a simple test with the students just to verify the learning, later, we made a statistical analysis to better know this data. Finally, we evaluate our course based on the presentation of these variables.

\subsection{Parameters analyzed}

First, each observed aspect will have a label to make it easier to make the appropriate associations in the graphics. The first attribute raised was the name of the participating girl's school (QESO1). Then, in ( $\mathrm{EESO2}$ ), the type of school was presented, and $89.5 \%$ are from state school, $7 \%$ are from municipal school and 3.5\% are from federal school. The next parameter observed is that all (100\%) girls are from urban city (QESO3). And almost all participants were female (89.3\%) and only $10.7 \%$ were male in (QESO 4 ). Then the age was observed in (QESO5), and that are $42.9 \%$ students between 13 and 15 years old, $50 \%$ between 15 and 18 years old and $7.1 \%$ students that are older than 18 years old 7.1\%. The size of family ( $\mathrm{EESO} 6$ ) was also observed and $78.6 \%$ students have families less or equal than 3 people and $21.4 \%$ students have families bigger than 3 people. In (QES 07) was observed that $53.6 \%$ parents live together in contrast $46.4 \%$ not.

In (QESO 8), about mothers' education: $7.0 \%$ does not have completed studies, $7.3 \%$ of students affirmed that their mother has early childhood education, $25.0 \%$ students affirmed that their mother has elementary school, $32.1 \%$ students affirmed that their mother has high school, 14.3\% students affirmed that their mother has Higher Education, $14.3 \%$ students affirmed they do not know. In (QESO 9), $4.3 \%$ of students affirmed that their mother works with Education, $14.3 \%$ students affirmed that their mother works with Services, 3.6\% students affirmed that their mother works with Health, 3.6\% students affirmed that their mother works with Business, 3.6\% students affirmed that their mother works with Security, $39.3 \%$ students affirmed that their mother does not work with and 
$25.1 \%$ affirmed that their mother works with other areas.

In (QES10), about fathers' education $7.0 \%$ does not have education, $10.7 \%$ of students affirmed that their father has early Childhood Education, $21.4 \%$ students affirmed that their father has elementary school, 25\% students affirmed that their father has high school 17.9\% students affirmed that their father has Higher Education, 17.9\% students affirmed they do not know. In (QES 11), $0.0 \%$ of students affirmed that their father works with Education, $14.3 \%$ students affirmed that their father works with Services, 3.6\% students affirmed that their father works with Health, 21.4\% students affirmed that their father works with Business, $10.7 \%$ students affirmed that their father works with Security, $10.7 \%$ students affirmed that their father does not work with and $53.6 \%$ affirmed that their father works with other areas.

In (QES 12), 64.3\% of instances has their mother working, 32.1\% of instances has their mother does not working and 3.6\% do not know. In (QES13), 71.4\% of instances has their father working, $17.9 \%$ of instances has their father does not working and $10.7 \%$ do not know. In (QES14), 82.1\% affirmed that the mother is the principal guardian, and $17.9 \%$ affirmed is the father. In (QES15) is the time spent from house to school, $25 \%$ spends between 5 and 15 minutes, 3.6\% spends between 15 and 25 minutes, $24.4 \%$ between 25 and 35 minutes, $17.9 \%$ spends between 35 and 45 minutes, $32.1 \%$ spends more than one hour.

In (QES16) is about failures, $78.6 \%$ never failed, $14.3 \%$ failed one time, $7.1 \%$ failed two times. In (QES17), 92.9\% is about the internet at home and $7.1 \%$ do not have. In (QES18), 57.1\% have computer and $42.9 \%$ do not have. In (QES19), $60.7 \%$ have video game and $39.3 \%$ do not have. In (QES20), 57.1\% have computer classes and $42.9 \%$ do not have. In (QES21), $92.9 \%$ have smartphone and $7.1 \%$ do not have. In (QES 22), 71.4\% have 1 - 5 free hours a day and $28.6 \%$ have 5 - 10 free hours a day.

Then we performed an evaluation of our extension course. In (QIT01) is about the reasons that influenced the teenagers to choose the course. In (QIT02) is about the most interesting things in the course. In (QIT03), 75\% instances relates that the course is very satisfactory and 25\% instances is mark with satisfactory. In (QIT 04 ) 100\% pretends to continue the course. In (QIT05), 3.6\% rated the course 3 stars, 17.9\% rated the course 4 stars and $78.6 \%$ five stars. In (QIT06) was a description about the course. Finally, the instances were evaluated using a 5 questions of OBI test, and results are from 0 points (worst score) to 5 points (best score)

\subsection{Statistical Analysis}

In Figure 3 a linear correlation of all questions was performed to see the correlation between all questions, so it was possible to measure the standardization of the relationship between the questions and indicate the strength and direction of the linear relationship between them. The chart indicates a greater positive correlation between questions QESO1, QES 0 5, QES10, and QES15, that is values greater than $(\geq+0.5)$. These questions are related to age, school, and time spent until institution. Among the correlated data, what struck the most was the fact that students who live closer to the institution where the course is applied had worse performances compared to other students.

The next step was to identify the characteristics of the students who differentiated the logic results. The first data to be analyzed was the contact with students' technology. Questions QES17, QES18, QES19, QES20, QES22, are related to this data. Figure 4(a) shows parallel coordinates related to these questions and the final result of the logic exam. 


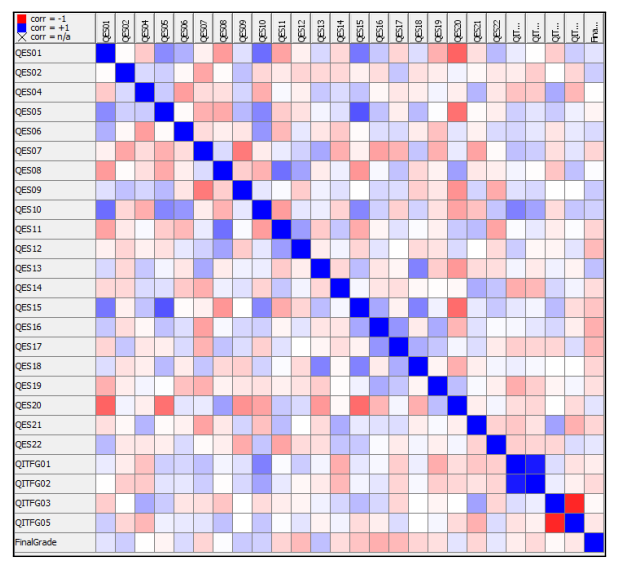

Figure 3. Linear correlation of all questions represented in a correlation matrix, which red values $(-1)$ represents strong inverse correlation, blue values $(+1)$ represents strong positive correlation and white values $(0)$ represents non correlation.

With this analysis, it was possible to identify the relationship between the technological contact and the result of the logic exam. In Figure 4(c) we can see that the students who

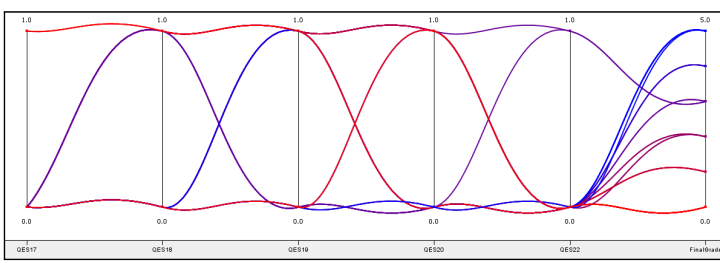

(a) Relation in having IT at home and scores.

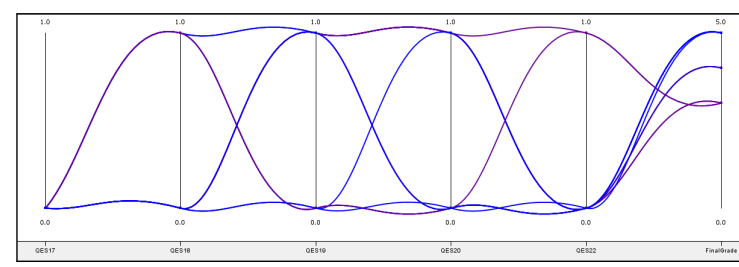

(c) Relation to best grades and IT at home.

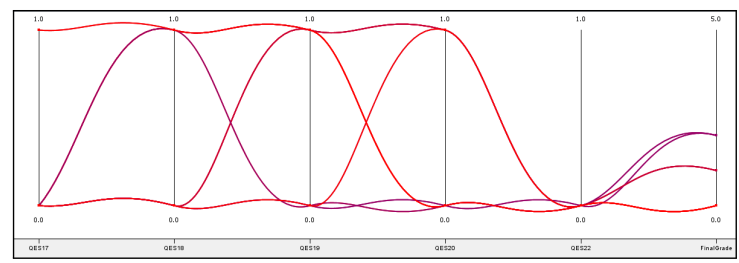

(e) Relation to worst grades and IT at home.

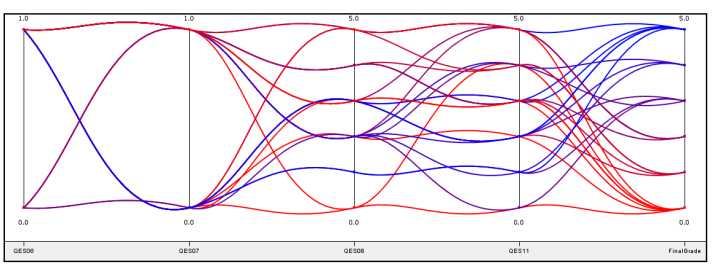

(b) Relation to family structure and score.

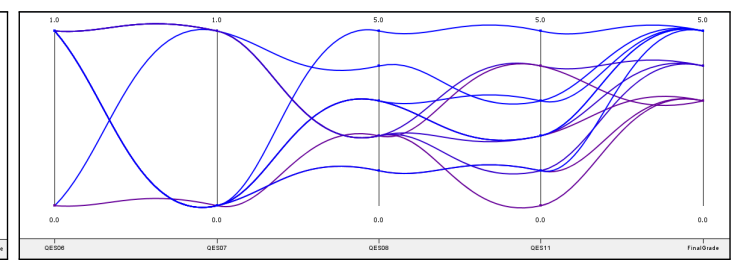

(d) Relation to best grades and family structure.

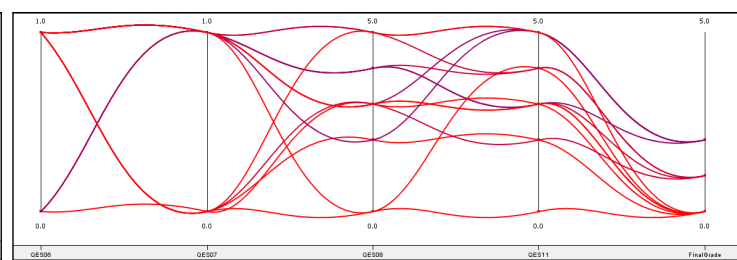

(f) Relation to worst grades and family structure.

Figure 4. Parallels coordinates where last column represents the students' test score and other columns are the parameters analyzed.

scored higher in the exam have more contact with technology than students who have little contact, especially in QES 17, correlating the fact that having internet at home is a good indication for students to also have good exam scores. In Figure 4(e) we can see the 
performance of students who have little contact with technology.

Another analysis is related to the student's parent situations Questions QESO6, QES 0 7, QES 0 8, QES11. These questions are related to parental social status. Figure 4(b) shows the parallel coordinates related to the questions with the result of the logic exam and parental analysis data. The results of the analysis indicate that the lower parents' educational level can affect the result of their children. Another relationship analyzed was the level of family relationship, families larger than 3 people and where the father is not present has a lower level in relation to the student. In Figure 4(d) it is possible to observe the relationship between the best grades in the logic exam and the questions in the logic exam. In Figure 4(f) it is possible to see the relationship between the worst grades and the result of the logic exam scores.

The development of the present study allowed an analysis of how the social life of the students can affect their score. With these results it was possible to know that interaction with technology influences the performance of girls in the project. Strategy games, where the right solution needs to be found, stimulate thinking. Teenagers who have a computer at home and have internet, they have more access to information and can also play games through the computer. These results showed the impact that these machines can bring on students education. In this analysis we can see the impact that family promotes in their children. As a result, the analysis of these data brings necessary information in the social knowledge of the IT and educational communities.

\subsection{Course Analysis}

The quali-quantitative research on the game programming course using Scratch was carried out aiming to improve the teaching planning and next courses project quality. The students' opinion was considered of great importance for the course completion. In Figure 5(a) we can see a graph showing what he liked most about the courses according to the appropriate suggestions.

Another data analyzed was the students' classification about the course. This classification is performed in QIT05. The purpose of this classification is to know how the course is viewed by students. In Figure 5(b) we can see the graph showing how students rate the course, $78.57 \%$ of students rated the course as 5 star, $17.86 \%$ rated the course 4 star and only $3.57 \%$ rated the course 3 stars, that means 2,1 or 0 have $0 \%$ of answers by students analysis. Showing the classes engagement and also that students are enjoying and learning in the IT for Girls course.

Finally, a cloud of words was made to assess which words appeared most from question QIT06. An extraction transformation and load (ETL) was made to remove unimportant words from this question. Thus turning it into a format that can be parsed and stored, making it have a better result. The cloud of words can be seen in Figure 5(c), showing that words "Good", "Interesting", "Cool", "Great", "Learn", "Amazing" and "Liked" are examples of words that most appeared. That means that girls are impressively enjoying with IT for Girls course. This being a good opportunity for us to improve, from the suggestions, the course offered in our institution.

Finally, a cloud of words was made to assess which words appeared most in description. An extraction transformation and load (ETL) was made to remove unimportant words from this question. Thus turning it into a format that can be parsed and stored, making it have a better result. The cloud of words can be seen in Figure 5(c). 


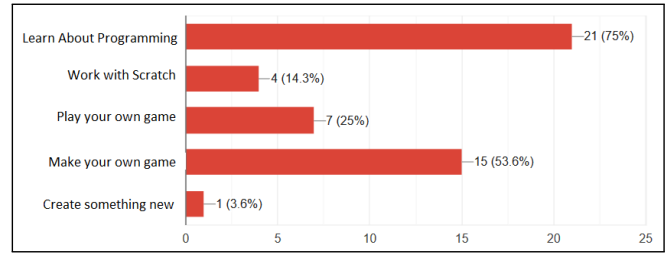

(a) Student's reason for project enrollment.

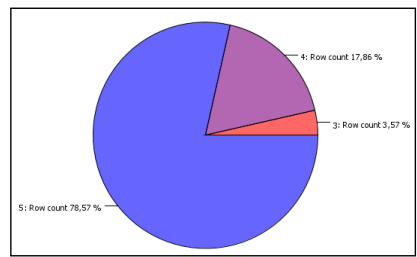

(b) Likert scale for course overall evaluation.

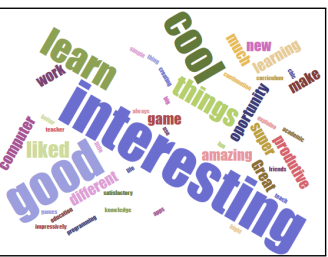

(c) Cloud of words engagement.

Figure 5. Quali-quantitative analisys of students' perceptions during IT for Girls project.

\section{Conclusions}

It is known that the insertion of girls in the technology area is low when compared to male adherence. However, efforts by the federal government have been maintained to strengthen this theme. The [Lima et al. 2021]'s SRL has shown that there are many authors around the world concerned with fostering projects in the field of STEM aimed at girls. So, based on this perspective, we launched a course called IT for Girls to strengthen actions to engage girls in STEM area. The course focus was teach logic for general purposes (robotics, games or math) and a game programming course on the Scratch platform. Initially, only girls were allowed to enter, however, we allowed boys to enter in order to fill vacancies, and 25 young people were enrolled in the course and $44 \%$ of that total completed the course.

To improve the continuity of our course, we performed analyzes including the time each student has free time (considered to be in the course offered by the institution), whether the student lives or studies, if the student has a cell phone, computer and internet at home (essential step to remodel the activities for home) that were previously planned. This initial phase was essential for the success of our project, since it is difficult for long extension projects to end with all the enrolled students. Among all the variables analyzed, the one that most correlated with the difficulty of getting a good grade in the initial test was the issue of having few technology at home, such as computers or internet.

As a future work, the social questionnaires are expected to be replicated with more questions involving the social environment, so that more complete descriptive analysis can be done for the most effective result and also using the Scratch tool as a student score tool. In addition, we hope to provide a laboratory space so that the girls in the extension project with little technology at home can use our institution's computer and internet resources. We will also assess the reasons for abandonment more clearly as a future work.

\section{References}

Alves, F. B. and Lima, D. A. (2018). Uso de la clasificación para el análisis y la minería de datos en la herramienta de enseñanza-aprendizaje google classroom.

Davis, S. (2020). Socially toxic environments: A ypar project exposes issues affecting urban black girls' educational pathway to stem careers and their racial identity development. The Urban Review, 52(2):215-237.

Eccles, J. S., Jacobs, J. E., and Harold, R. D. (1990). Gender role stereotypes, expectancy effects, and parents' socialization of gender differences. Journal of social issues, 46(2):183-201. 
Ferreira, M. E., Lima, D. A., and Silva, A. (2019). Data analysis for robotics and programming project evaluation involving female students participation. In 2019 Latin American Robotics Symposium (LARS), 2019 Brazilian Symposium on Robotics (SBR) and 2019 Workshop on Robotics in Education (WRE), pages 417-422. IEEE.

García-Holgado, A., Díaz, A. C., and García-Peñalvo, F. J. (2019). Engaging women into stem in latin america: W-stem project. In Proceedings of the Seventh International Conference on Technological Ecosystems for Enhancing Multiculturality, pages 232239.

Glover, A., Harries, S., and Jones, M. (2018). An evaluation of a project aimed at increasing participation of young women in stem activities and training in wales. International Journal of Gender, Science and Technology, 10(3):432-440.

Guiso, L., Monte, F., Sapienza, P., and Zingales, L. (2008). Culture, gender, and math. Science, 320(5880):1164-1165.

Hill, C., Corbett, C., and St Rose, A. (2010). Why so few? Women in science, technology, engineering, and mathematics. ERIC.

Hill, M. A. and King, E. (1995). Women's education and economic well-being. Feminist Economics, 1(2):21-46.

Kimmel, M. S. et al. (2005). The history of men: Essays on the history of American and British masculinities. SUNY Press.

Lima, D. A., Ferreira, M. E. A., and Silva, A. F. F. (2021). Machine learning and data visualization to evaluate a robotics and programming project targeted for women. Journal of Intelligent \& Robotic Systems, 103(1):1-20.

Lima, D. A., Zati, A. F., and Silva, E. C. (2017). Análise de dados no google classroom para auxiliar na diminuição do distanciamento transacional nas disciplinas da área de lnformática. In TISE Conferência Internacional sobre Informática na Educacão.

Mich, O. and Ghislandi, P. (2019). Young girls and scientific careers: may a course on robotics change girls' aspirations about their future? the roboestate project. QwertyOpen and Interdisciplinary Journal of Technology, Culture and Education, 14(2):88109.

Mirici, S., Gencer, İ., and Gündüz, S. (2019). The impact of stem project writing education on candidate female teachers' attitudes, their semantic perceptions and project writing skills towards stem education. International Journal of Curriculum and Instruction, 11(2):255-272.

Schnittker, J., Ettl, K., and Welter, F. (2018). Strengthening the self-and external perceptions of young women stem professionals (ywsp) during career entry and advancement: a research project. In Proceedings of the 4th Conference on Gender \& IT, pages 51-53.

Valentine, T. and Darkenwald, G. G. (1990). Deterrents to participation in adult education: Profiles of potential learners. Adult education quarterly, 41(1):29-42.

Zeldin, A. L., Britner, S. L., and Pajares, F. (2008). A comparative study of the selfefficacy beliefs of successful men and women in mathematics, science, and technology careers. Journal of Research in Science Teaching: The Official Journal of the National Association for Research in Science Teaching, 45(9):1036-1058. 